\title{
Modifications on the Alternative Method for Cochlea Implantation
}

\author{
R.A. Tange \\ Department of Otorhinolaryngology, \\ University Center of the University of Utrecht, Utrecht \\ The Netherlands
}

\section{Introduction}

House 1 introduced the classic surgical technique for cochlear implantation. This surgical technique consists of a mastoidectomy and a posterior tympanotomy and this approach is still worldwide the most frequently used technique for cochlear implantation. This classic surgical technique uses a complete mastoidectomy with an attempt to leave a bony overhang posterior and superiorly to capture the proximal electrode lead 2,3. After the complete mastoidectomy a posterior tympanotomy is performed with special attention to the facial nerve and the chorda tympani. Through the large posterior tympanotomy (intraoperative facial nerve monitoring is mandatory) a cochleostomy can be performed for electrode insertion. The classic technique has proven to be sufficient in the vast majority of cochlear implantations. Still complications concerning the facial nerve can occur due to the fact of drilling within a millimetre of the facial nerve making the posterior tympanotomy 4,5 To avoid negative side effects as a temporary or permanent injury to the facial nerve Kronenberg et al ${ }^{6}$,Kiratzidis ${ }^{7}$ and later Hausler ${ }^{8}$ designed a different approach in which no mastoidectomy was needed to create the pathway towards the cochleostomy. These new cochlear implantation techniques without a mastoidectomy and a posterior tympanotomy seem to be safe and effective procedures. After experienced the classic approach of cochlear implantation our cochlear implant team moved over to the new innovative alternative surgical approach introduced by Joan Kronenburg in 2001. Our first positive experiences with the suprameatal approach and our modifications have been published in $2004{ }^{9}$. Our method consists of a number of following steps as shown in the table 1.

\begin{tabular}{|l|l|}
\hline \multicolumn{2}{|l|}{ Steps in our approach for cochlear implantation } \\
\hline $\mathbf{1}$ & Retroauriculair skin incision : middle ear approach \\
\hline $\mathbf{2}$ & $\begin{array}{l}\text { Creating of the suprameatal tunnel towards incus : } \\
\text { Making a connection between middle ear and tunnel }\end{array}$ \\
\hline $\mathbf{3}$ & Second temporal incision to create the well for the cochlear implant device \\
\hline $\mathbf{4}$ & Subcutaneous subperiostal tunnel between two incisions (plastic canula) \\
\hline $\mathbf{5}$ & $\begin{array}{l}\text { Imbedding implant in temporal area with guiding the active array (and ball } \\
\text { electrode) towards retro auricular incision. }\end{array}$ \\
\hline $\mathbf{6}$ & Creating cochleostomy through external auditory canal. \\
\hline $\mathbf{7}$ & Insertion of the array via combined approach into the cochlea \\
\hline
\end{tabular}

Table 1. 


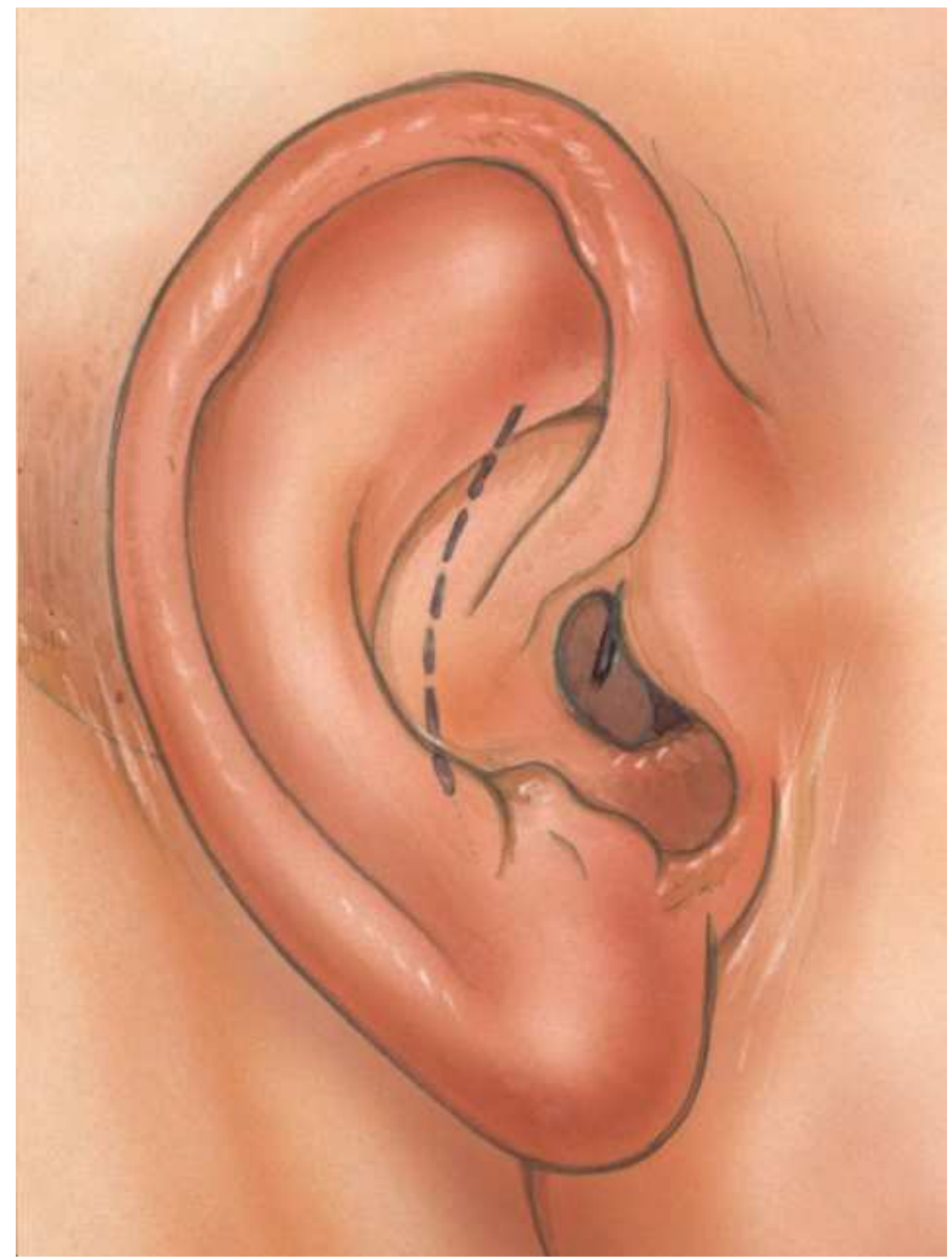

Fig. 1. Small retroauriculair incision (step1) 


\section{Retroauriculair skin incision: Middle ear approach}

All our patients are operated in general anaesthesia. After sterile draping the incisions and the site for the internal processor are marked. After local sub and intra cutaneus injection of adrenalin 1:100.000 the first retroaricular incision ( $5 \mathrm{~mm}$ from the tragus fold) of $2 \mathrm{~cm}$ is made. The periost is cut in and elevated to explore the introitus of the external ear canal. The skin of the canal is elevated without opening the external ear. The annulus of the eardrum is carefully elevated and special attention is given to the course of the chorda tympani. The middle ear will be inspected then. Important anatomical structures to distinguish are the round window nice and the stapes incus complex. In cases of a curved bony external ear canal sometimes lateral some bony "overhang" need to be removed to facilitate optimal view into the middle ear and to ease the cochleostomy in a later phase of the surgery. The position of the cochleostomy is located by the point of junction of a line drawn anteriorly from the middle of the round window niche intersecting a line drawn inferiorly from the oval window niche. The middle ear area is now filled with a sterile sponge to prevent entering bone dust in the middle ear and to open the middle ear approach.

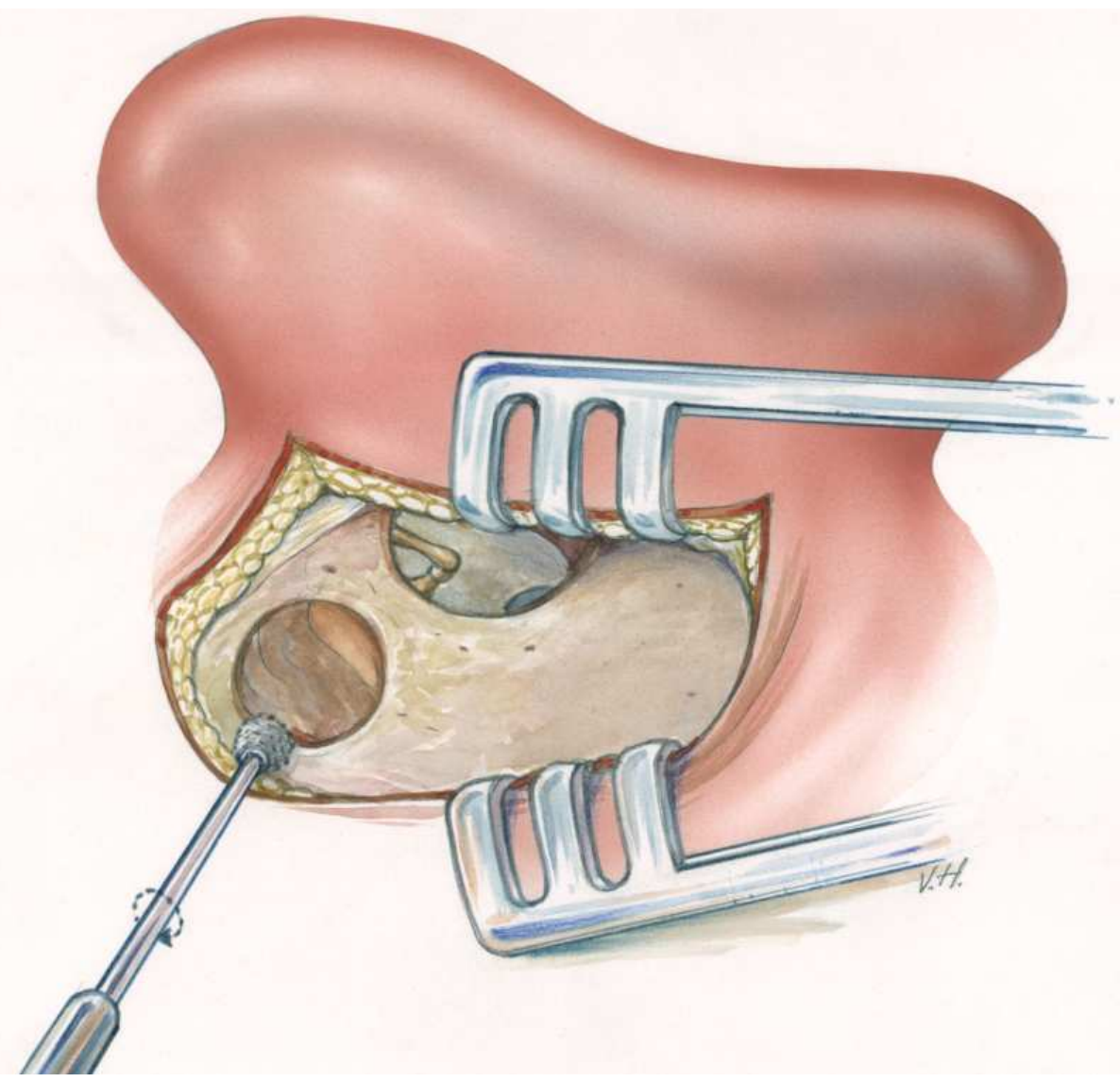

Fig. 2. Middle ear approach by retroauriculair incision (step1) 


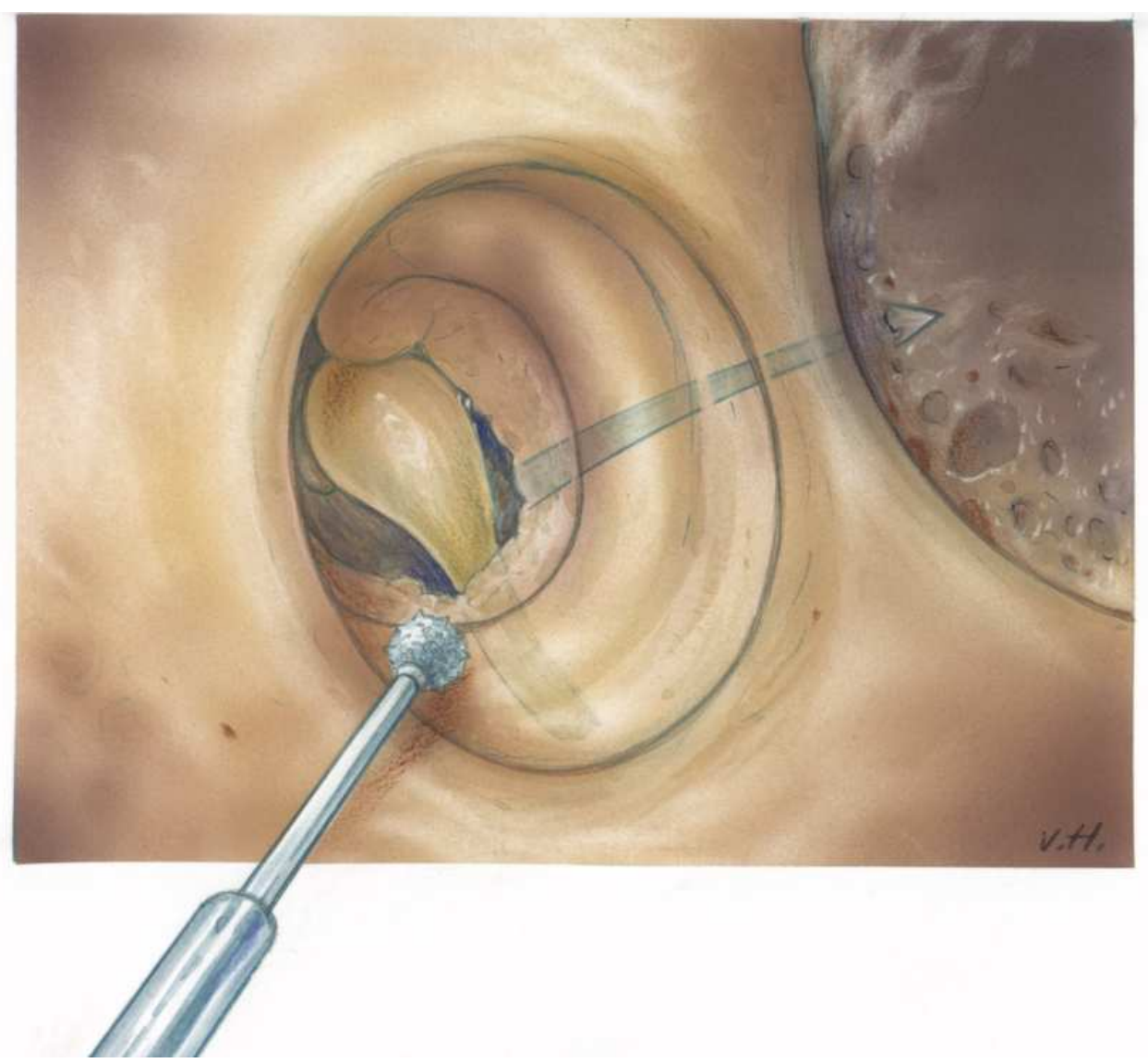

Fig. 3. Creating of the suprameatal tunnel towards incus : Making a connection between middle ear and tunnel (step 2)

\section{Creating of the suprameatal tunnel towards incus: Making a connection between middle ear and tunnel}

In the following phase of our approach a small tunnel is drilled from the suprameatal spine towards the body of the incus. Preoperatively thorough analyzing op the preoperative CTscans of the operating ear is obligator. Axial and coronal images predict the state of the mastoid and the space for the creation of the suprameatal tunnel. According the scans one can decide whether to perform the alternative approach for cochlear implantation or not. On the other hand it is of course always possible to change from our alternative technique to the classical approach in cases anatomical variations. In our series we have only changed towards the classical method in two cases. The small bony tunnel canal is drilled from behind the suprameatal spine to the posterior attic. When the pneumatized mastoid is opened with a sharp $5 \mathrm{~mm}$ drill the next orientation point is the horizontal semicircular bony canal near the short process of the incus. A limited posterior atticotympanotomy is 
performed to visualize the short process if the incus. The space between the lateral edge of the short process of the incus and the canal wall is now opened and must be enlarged by drilling with the diamond burrs $(1.5-2 \mathrm{~mm})$. The long process of the incus becomes visible and in most of the cases the incudo-stapedial joint can be observed. Introducing the gentle curved pick needle through the created opening between incus and canal wall the pathway for the array towards the cochlea in the middle ear is tested. Using this approach there is no danger for the facial nerve and the chorda tympani. When we decide that the this supra tympanotomy approach is sufficient for the introduction of the array a second sterile sponge is placed in the created tunnel. The retro auricular incision is closed with one temporary suture.

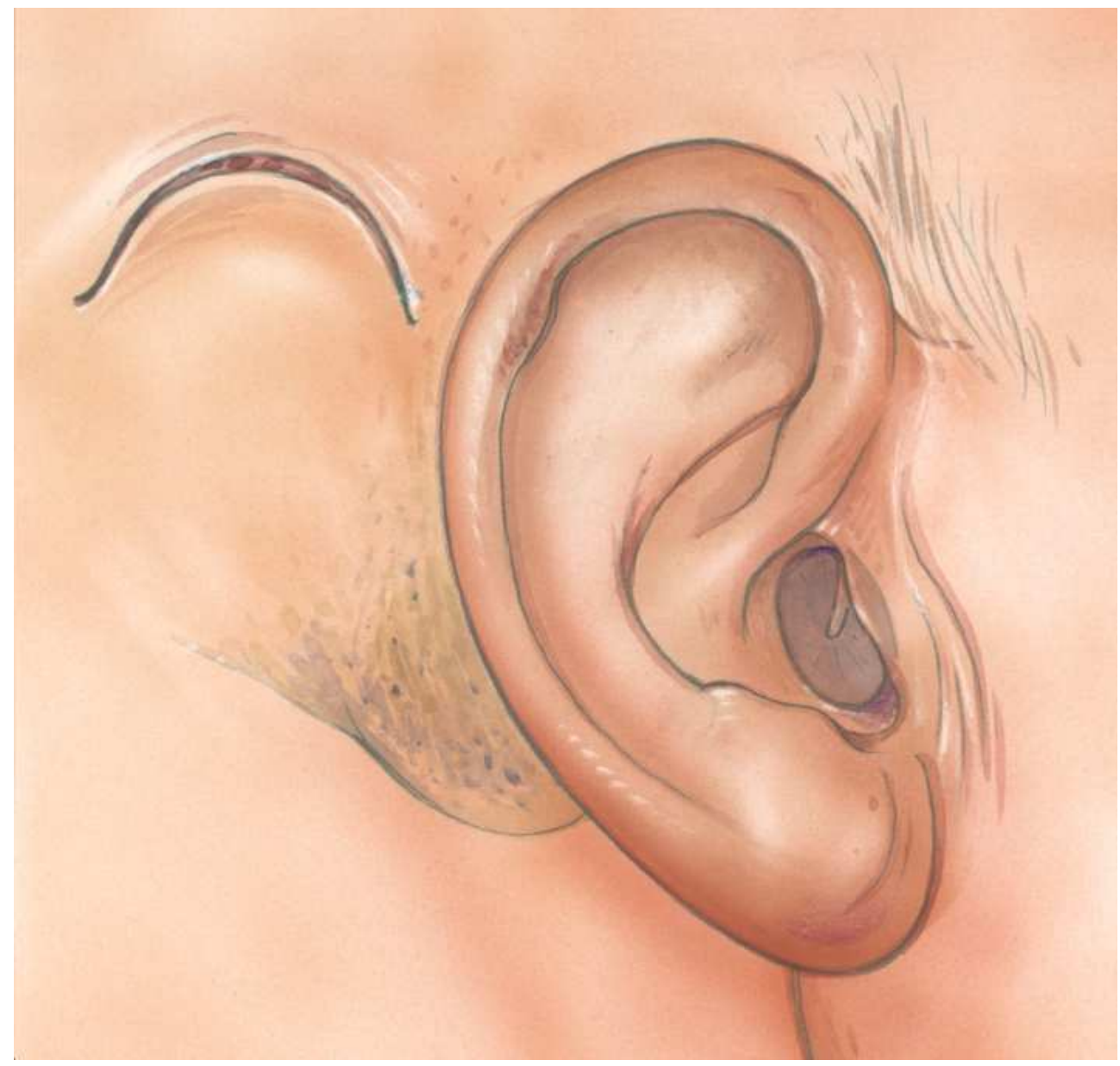

Fig. 4. Second temporal incision to create the well for the cochlear implant device (step 3) 


\section{Second temporal incision to create the well for the cochlear implant device}

Different from the classic method of implantation and the methods describes by Kronenberg Kiratzidis and other we do not extent the retro auricular skin incision superoposteriorly to expose the temporomastoid region for the drilling of the well for the device. To keep the natural tension of the skin and the periost of the temporomastoid region we make a small semicircular skin incision with a diameter of about $2.5-3 \mathrm{~cm}$ at the site where the well for the device is planned. When the skin and the subcutaneous tissue is elevated the periost covering the temporal bone is incised with an opposite semicircular periost incision. With this modification the two incisions will not be in the same level and the skin/periost tension over the implanted device is distributed equally this way. According the size of the cochlear implants used the well can be created through the second skin incision. Because of the semicircular shape of the incision optimal room is created for the implantation of the device without losing much tension of the skin and periost. Tie-down holes are not necesssary using our procedure. The tension of the skin and periost keep the implant safe in the well of the temporal bone. When the well is created a subperiost tunnel in created between the "well incision" and the retro auricular incision. A sterile plastic canula with a diameter of about $3 \mathrm{~mm}$ is inserted in this sub periostal tunnel.

At this moment the cochlear implant device is unpacked and introduced into the "well incision" after making sub periost room for the magnet. The array (and the ball electrode) are introduced into the plastic canula. This canula is then gently pulled towards the retro auricular incision presenting the array (and the ball electrode) near the suprameatal tunnel. The "well incision" is now sutured in two layers.

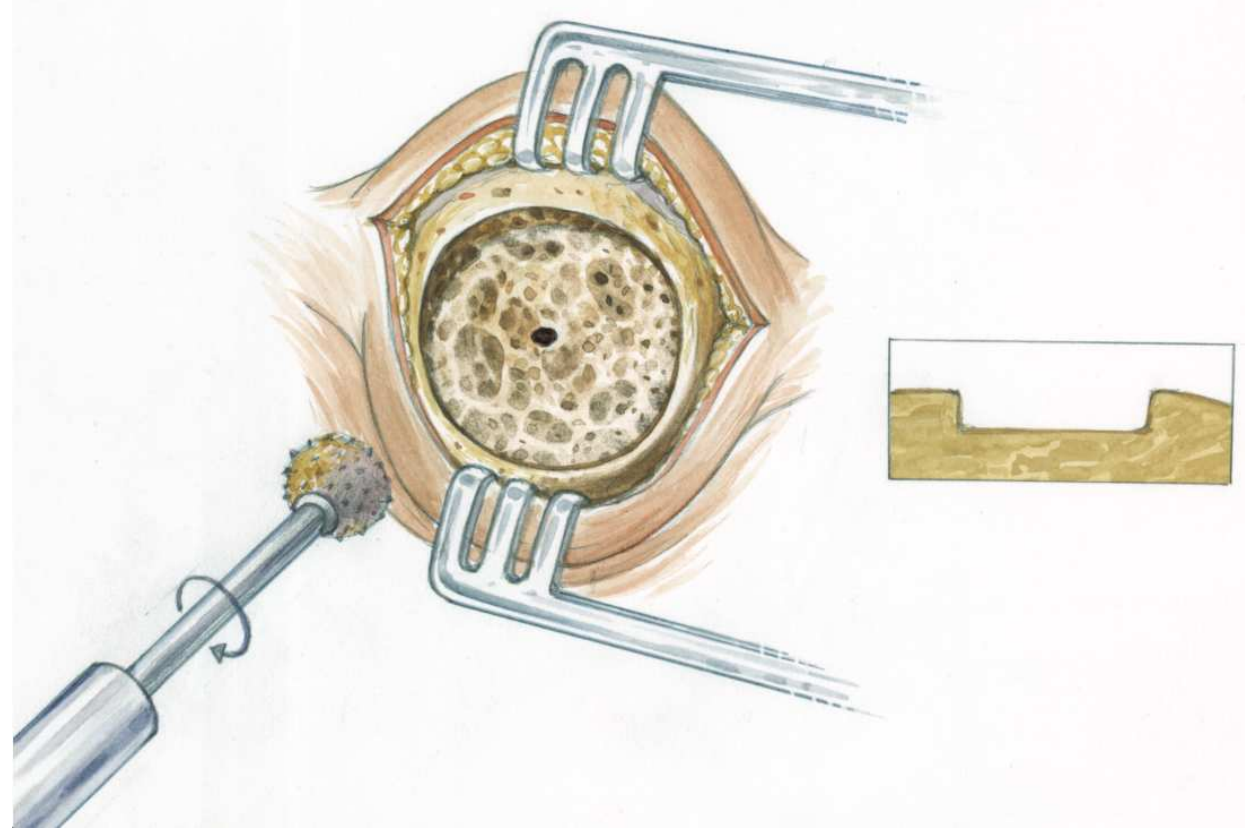

Fig. 5. Creation of the well for the cochlear implant device (step 3) 


\section{Creating cochleostomy through external auditory canal}

Having the array near to the cochlea the time has arrived to create the cochleostomy. The two protecting sponges are removed and the suprameatal tunnel and middle ea are cleaned. At the point where a junction of a line drawn anteriorly from the middle of the round window niche intersecting a line drawn inferiorly from the oval window niche a cochleostomy is created through the external ear canal. With a 1.5 diamond burr, the bone of the promontory is drilled away to a dept of approximately $1.5 \mathrm{~mm}$ until the endosteum of the scala tympani is visualized. Then a 1-mm bur is used to complete the bony removal, with an attempt to leave the endosteum intact until all bone work is done. With a sharp pick the endosteum is incised and the sharp bony edges of the cochleostomy are removed. The undersurface of the basilar membrane is now visible and lumen of the scala tympani is open to insert the array of the cochlear implant. It is important to attempt to limit the amount of bone dust into the cochlea to prevent new bone formation in the inner ear.

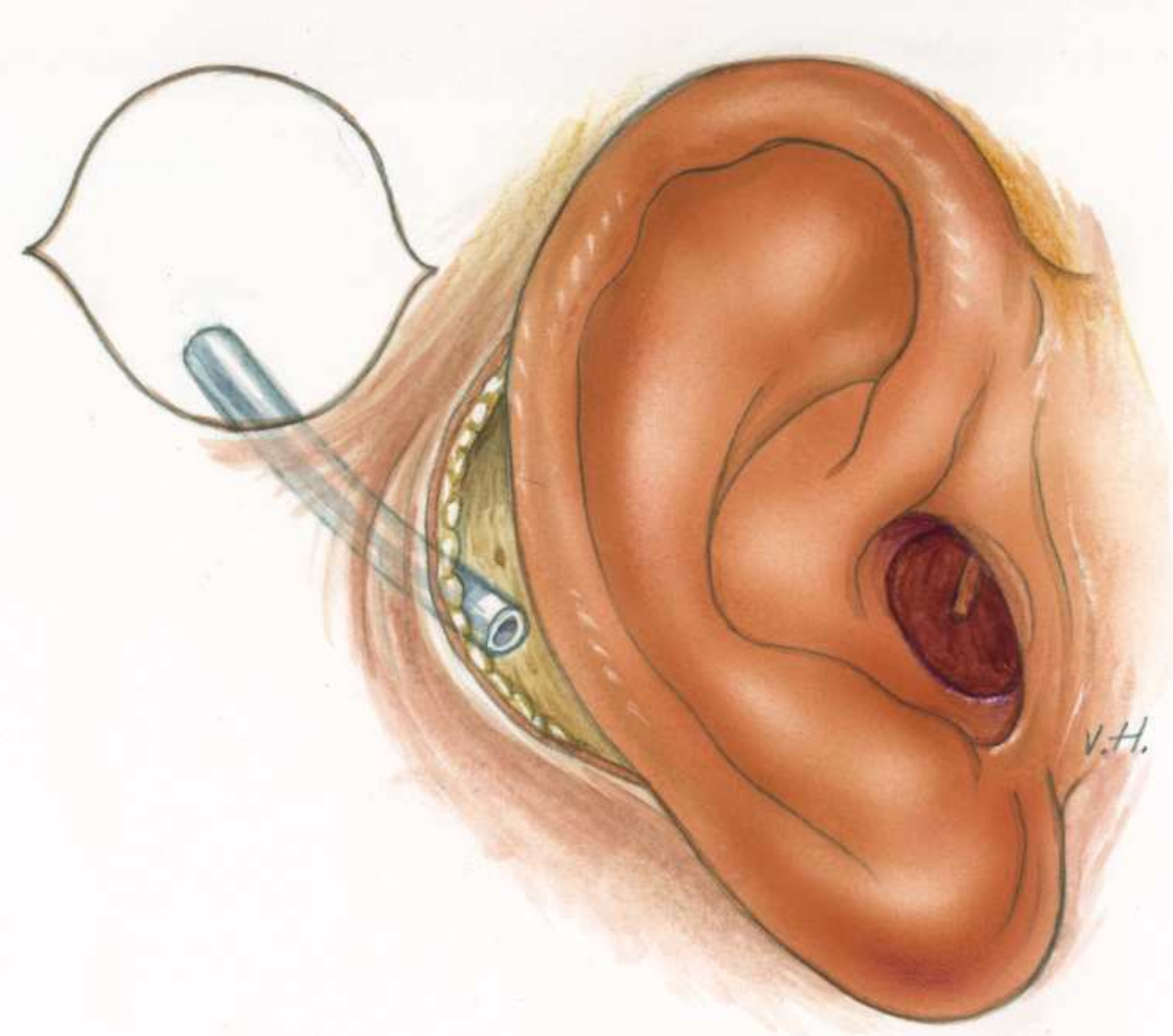

Fig. 6. Subcutaneous subperiostal tunnel between two incisions (plastic canula) (step 4) 


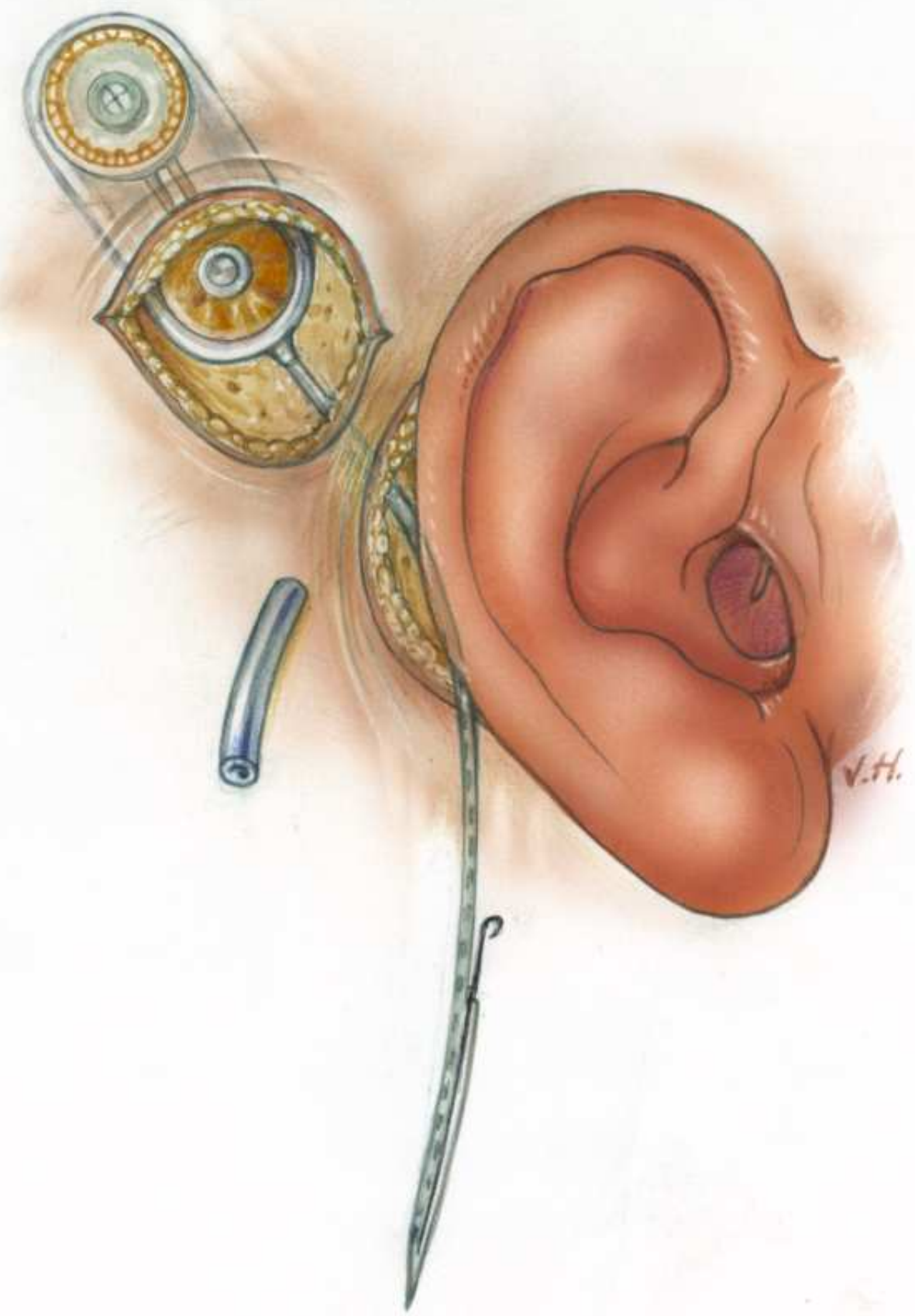

Fig. 7. Imbedding implant in temporal area with guiding the active array (and ball electrode) towards retro auricular incision. (step 5) 


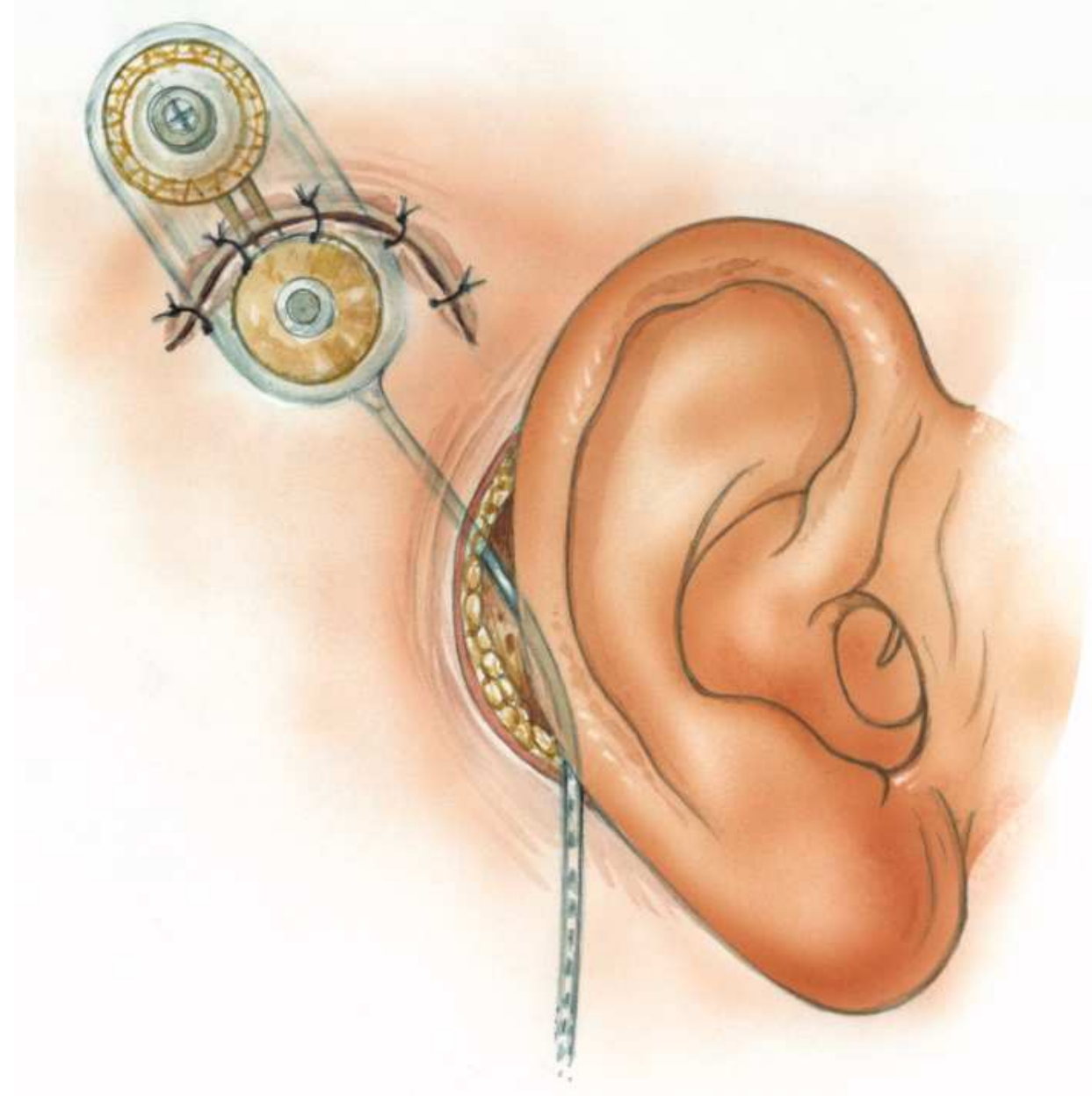

Fig. 8. Closure of the $2^{\text {nd }}$ temporal incision (step 5)

\section{Insertion of the array via combined approach into the cochlea}

After the creation of the cochleostomy the electrode insertion can be performed. Using instruments as a micro-jeweller forceps, insertion claw, suction tip or angled pick the electrode is guided through the suprameatal tunnel towards incus. The tip of the electrode is than introduced into middle ear along the long process of the incus. Via the external ear canal the tip of the electrode is now visible and can be guided towards the cochleostomy. Prior to the insertion we use a drop of lubricant hyaloron acid (Healon) to ease the insertion of the electrode. The electrode is now gently inserted into the cochlea advancing the array 1 to $2 \mathrm{~mm}$ at the time. Halfway the insertion (white mark Nucleus device) the stylet of the 


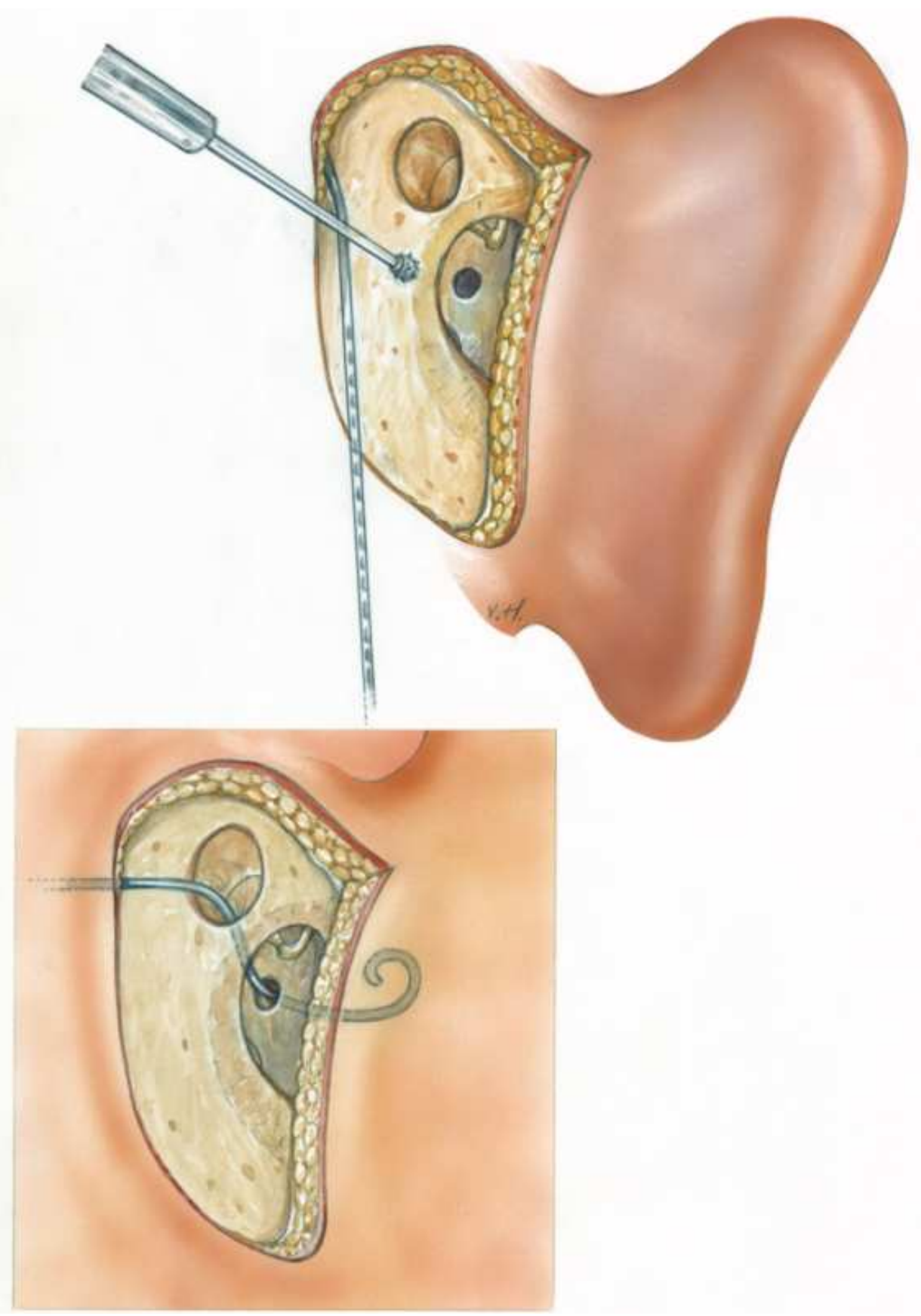

Fig. 9. Creating cochleostomy through external auditory canal and insertion of the array via combined approach into the cochlea. (step $6 \& 7$ ) 
array is gently removed while the array is pushed off-stylet in to the cochlea. Using the insertion claws a total insertion is pursued and will be possible in almost all the cases. Sometimes some tiny pieces of fascia can be placed around the electrode at the cochleostomy area. When the implantation of the electrode into the cochlea is performed the array is fixed in the opening of suprameatal tunnel by local bone dust. The retroauriculaire incision is now carefully sutured in two layers and a dressing of the external ear canal is placed through the external meatus. At this point the implanted device is tested by electrophysiological or neural response measurements. A transmitter coil in a sterile endosheath is placed on the magnet area of the implant. Electrode impedances are measured and other electrically tests like neural response telemetry ( NRT/NRI) can be performed depending the device used. These tests are important to assure that the implant is functioning properly and that the patient receives an auditory stimulus and responds appropriately. In our centre, the 3D-RX, a way of three dimensional rotational imaging with a mobilized $\mathrm{C}$ arm in the OR is now the standard procedure for illustrating the electrode position in the cochlea right after implantation. This method is described recently by Carelsen et al 9 When all the electrophysiological or neural response measurements are in favour of a good functioning implant and patient responses are adequate together with normal imaging of the array in the cochlea the surgery is ended.

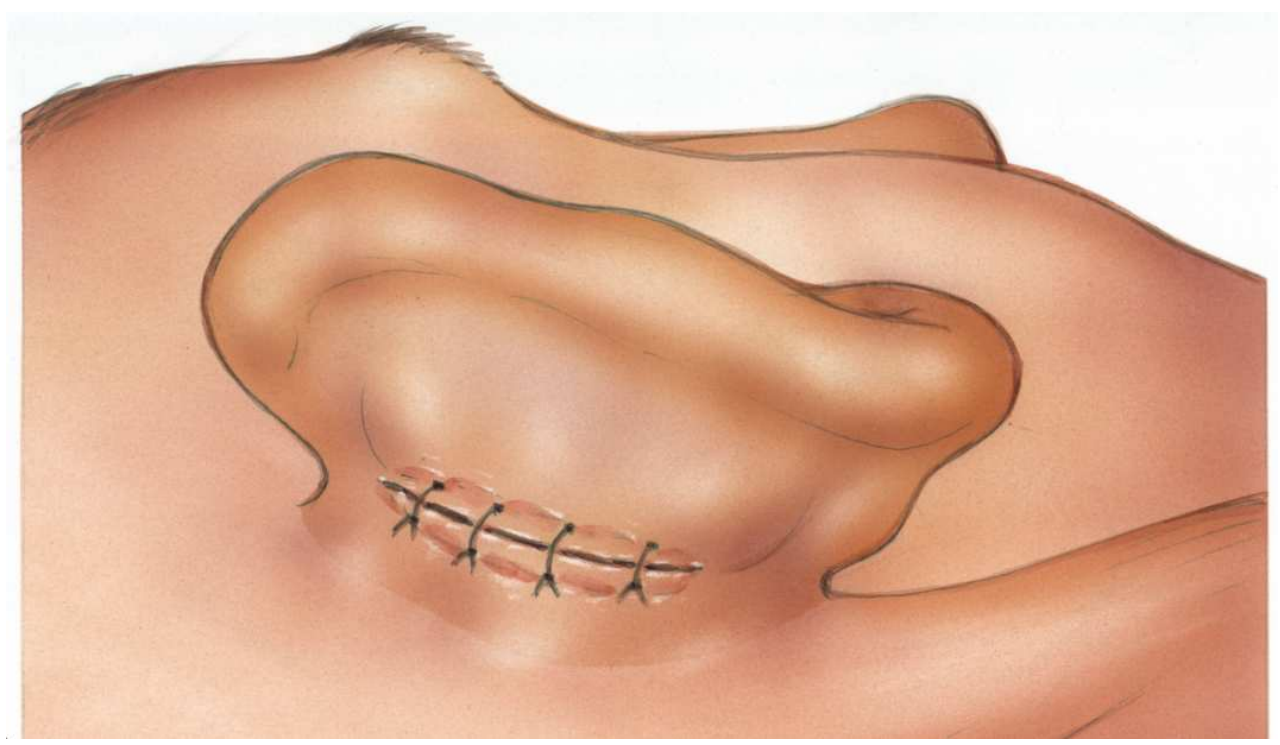

Fig. 10. Closure of the small retroauriculair incision

\section{The data of our approach for cochlea implantation}

We started our cochlear implant programme in 2003 and, to date, 260 patients have received their cochlear implant according the suprameatal method. Initially, we started our cochlear implant programme using the classic method with mastoidectomy and posterior tympanotomy approach. But soon we altered our cochlear implant strategy in favour of the 
new innovative alternative surgical approach. The mean age of the 260 patients implanted was 39.6 years (1.0-82.3 years) and the mean duration of deafness was 26.3 years (0.3-66.0 years). The main etiology of the deafness of our cochlear implant group was a congenita1 hearing $(31.4 \%)$ and a progressive sensorineura1 hearing $((24.8 \%)$. Other causes of deafness were meningitis $(13.3 \%)$ and otosclerosis $(6.7 \%)$. Prelingua1 deafness and postingua1 deafness accounted for $51.0 \%$ and $49.0 \%$ respective1y. Four different types of cochlear implants have been used for implantation; the Nucleus $^{\circledR 24 C^{2} \text { ountour }}{ }^{\mathrm{TM}}$, the Nucleus ${ }^{\circledR 24 C o u n t o u r}{ }^{\mathrm{TM}}$ Advance with Softip ${ }^{\mathrm{TM}}$, Advanced Bionics ${ }^{\circledR}$ HiFocus Helix and Medel Sonata ${ }^{\circledR}$ Ti100. We recorded the duration of surgery for all cochlear implantations. The mean duration of cochlear implantation was 111.7 minutes. The shortest procedure accounted for 57 minutes; the longest duration of surgery was 261 minutes which was a consequence of difficult insertion of the electrode due to otosclerosis of the cochlea. With respect to the duration of surgery we excluded the time of audiological measurements after implantation. Studying the data of last years there is no tendency of declination of the duration time of the surgery. The mean time of surgery stays constant during the study period which means there is no learning curve with respect to duration of the surgery. Maximum time of surgery in two procedures was prolonged in 2004 and 2006. In both procedures the insertion of the electrode was extremely difficult due to otosclerosis of the cochlea and secondly by a low-lying middle fossa dura. Complication of our approach can be divided into minor and major complications. The minor complication rate was 23 per cent. These complications consisted out of tinnitus (7.2\%), vertigo postoperatively $(5.2 \%)$, eardrum perforation $(1.3 \%)$, haematoma $(1.3 \%)$ and other some causes $(3.8 \%)$. We did have one case (otosclerosis) of mild facial nerve stimulation which could be managed by switching off a number of electrodes. All minor complications were successfully overcome by conservative therapy. The major complications were five in number. The overall major complication rate was $3 \%$. All complications developed postoperatively. The major complications consisted of extrusion of the implant due to wound infection in two cases, a fausse route of the electrode 11 , a misdirected electrode in severe otosclerosis and a case of explantation due to psychiatrically illness and pain sensations. All five cases of major were re-implanted and ended up successfully thereafter except for the patient with the psychiatrically illness. She still has all kind of complaints in spite of a perfect functioning device and perfect wound healing. In our series we had one case of a device failure (the speech recognition declined one year after implantation) which required explantation and re-implantation. Concerning the hearing gain achieved with the cochlear implants the average gain for the whole group of adults was almost $84 \%$ CVC. Average preoperative CVC was $12 \%$. Of the whole group implanted only two non users of the hearing device which makes $99,5 \%$ happy users. In a study 12 on the postoperative status of the mastoid cavity after cochlear implantation with our mastoid saving surgical method we compared pre- and postoperative protocolair prepared CT-scans of the mastoid cavity of 79 patients. In 76 cases no abnormalities were observed in the mastoid of the operated ear for cochlear implantation. In two cases of otosclerosis swollen mucosa was observed without any clinical relevance. In one case (a child) opicafication of the whole mastoid and middle ear was observed without destruction of the structures of the mastoid. We concluded with others ${ }^{13}$ from these data that the delicate structures of the mastoid cavity can be kept intact using a mastoid saving surgical approach. 


\section{In conclusion}

Our alternative approach for cochlea implantation has like the methods introduced by Kronenberg and others been proven a reliable alternative approach for cochlear implantation. It is a functional approach leaving the delicate structures of the pneumatized mastoid intact. An important fact of this innovative approach is the safety for the facial nerve. It is almost impossible to injure the facial nerve or the chorda tympani with this approach. Bilateral simultaneous cochlear implantation using the alternative approach is possible and recommended to reduce the extra surgery time. Because of our two small incisions approach to fix the processor the creation of tie-down holes are not necessary anymore which reduces the extra risk of infection of the implant. In our opinion it is of great importance to use the combined approach in cases of anatomical changes of this area as in severe cochlear otosclerosis. An other great advantage of the suprameatal approach with all its variations is the possibility to switch over when needed to the classic surgical approach introduced may years ago.

\section{References}

[1] House W.F. Cochlear implants. Ann.Otol.Rhinol. Laryngol. 1976;8 (suppl.27) : 2-7

[2] Clark G.M.A. : A surgical approach for a cochlear implant : An anatomical study. J.Laryngol.Otol. $1975 ; 89 / 1$ : 9-115

[3] Goycolea M.V., Papparella M.M., Muchow D. Mastoidectomy tympanotomy approach for cochlear implantation. Laryngoscope 1987; 97 : 766-771

[4] Cohen N.L., Hoffman R.A. Complications of cochlear implant surgery in adults and children. Ann. Otol.Rhinol. Laryngol. 1991; $100: 708-711$

[5] Kempf H-G. Tempel S. Johann K. Lenarz Th. Complications in cochlear implant surgery. Laryngo- Rhino- Otologie. 1999. Vol 78(10) : 529-537

[6] Kronenberg J. Migirov L. Dagan T. Suprameatal approach: New surgical approach for cochlear implantation. Journal of Laryngology \& Otology. 2001. Vol 115(4): 283-285

[7] Kiratzidis T. "Veria operation" : Cochlear Implantation without a mastoidectomy and a poaterior tympanotomy - a new surgical technique. In : Kim C.S.,Chang S.O.,Lim D. (eds): Updates in Cochlear Implantations. Ad.Otorhinolaryngol. Basel Karger 2000 vol 57 pp 127-130

[8] Hausler R. Cochlear implantation without mastoidectomy: The pericanal electrode insertion technique. Acta Oto-Laryngologica. Vol 122(7) (pp 715-719), 2002.

[9] Tange R.A. Grolman W. Mastoid saving surgical approach (MASSA) and our experience with a new electrode with softip for cochlear implantation Journ Ind.Soc.Otol. Vol 2 nr 1\&2 2004 29-32

[10] Carelsen B, Grolman W, Tange RA, Streekstra GJ, van Kemenade P, Jansen RJ, Freling NJ, White M, Maat B, Fokkens WJ. Cochlear implant electrode array insertion monitoring with intra-operative 3D rotational X-ray. Clin Otolaryngol. 2007 Feb;32(1):46-50.

[11] Tange R.A. Grolman W., Maat A. Intracochlear misdirection implantation of a cochlear implant. Acta Otolaryngol (Scand.) 2006 126:6 : 650-652

[12] Tange R.A.,Grolman W. Het mastoid na CI implantatie met de mastoid-sparende benadering . Ned.Tijdschr. KNO-Heelk 2007 ; 13(4) 22-223 
[13] Kronenberg J.,Migirov L.The role of mastoidectomy in cochlear implant surgery. Acta Oto-Laryngologica. 2003 Vol 123(2) ; 219-222. 


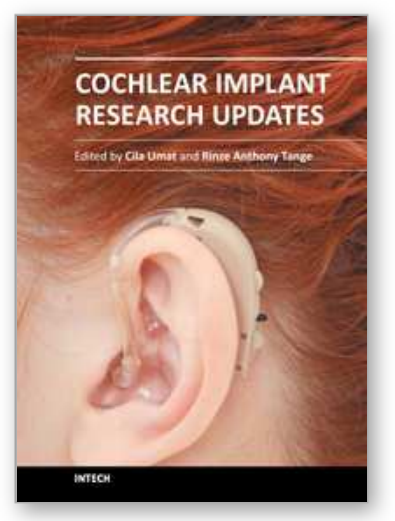

\author{
Cochlear Implant Research Updates \\ Edited by Dr. Cila Umat
}

ISBN 978-953-51-0582-4

Hard cover, 232 pages

Publisher InTech

Published online 27, April, 2012

Published in print edition April, 2012

For many years or decades, cochlear implants have been an exciting research area covering multiple disciplines which include surgery, engineering, audiology, speech language pathology, education and psychology, among others. Through these research studies, we have started to learn or have better understanding on various aspects of cochlear implant surgery and what follows after the surgery, the implant technology and other related aspects of cochlear implantation. Some are much better than the others but nevertheless, many are yet to be learnt. This book is intended to fill up some gaps in cochlear implant research studies. The compilation of the studies cover a fairly wide range of topics including surgical issues, some basic auditory research, and work to improve the speech or sound processing strategies, some ethical issues in language development and cochlear implantation in cases with auditory neuropathy spectrum disorder. The book is meant for postgraduate students, researchers and clinicians in the field to get some updates in their respective areas.

\title{
How to reference
}

In order to correctly reference this scholarly work, feel free to copy and paste the following:

R.A. Tange (2012). Modifications on the Alternative Method for Cochlea Implantation, Cochlear Implant Research Updates, Dr. Cila Umat (Ed.), ISBN: 978-953-51-0582-4, InTech, Available from:

http://www.intechopen.com/books/cochlear-implant-research-updates/modifications-on-the-alternativemethod-for-cochlea-implantation

\section{INTECH}

open science | open minds

\section{InTech Europe}

University Campus STeP Ri

Slavka Krautzeka 83/A

51000 Rijeka, Croatia

Phone: +385 (51) 770447

Fax: +385 (51) 686166

www.intechopen.com

\section{InTech China}

Unit 405, Office Block, Hotel Equatorial Shanghai

No.65, Yan An Road (West), Shanghai, 200040, China

中国上海市延安西路65号上海国际贵都大饭店办公楼 405 单元

Phone: +86-21-62489820

Fax: $+86-21-62489821$ 
(C) 2012 The Author(s). Licensee IntechOpen. This is an open access article distributed under the terms of the Creative Commons Attribution 3.0 License, which permits unrestricted use, distribution, and reproduction in any medium, provided the original work is properly cited. 